\title{
Evolução das aplicações e efeitos da política de crédito rural no estado do Amazonas
}

\author{
Carina Chagas Madeira de Souza ${ }^{1}$ \\ Marcos Antônio Souza dos Santos ${ }^{2}$ \\ Fabrício Khoury Rebello ${ }^{3}$ \\ Cyntia Meireles Martins ${ }^{4}$
}

\begin{abstract}
RESUMO
O crédito rural exerce papel fundamental no crescimento e desenvolvimento econômico, pois é um instrumento que viabiliza recursos financeiros para investimentos em infraestrutura produtiva, custeio e comercialização da produção agropecuária. Neste estudo, avaliou-se o perfil e a distribuição dos recursos de crédito rural no estado do Amazonas no período de 1990 a 2017. Utilizou-se a base de dados do Banco Central do Brasil (BACEN) para cálculo do Índice Normalizado de Crédito Rural (INCR), cujos resultados mostram a dinâmica espacial da alocação dos financiamentos. Estimou-se o Índice de Gini para aferir o nível de concentração no número de operações e valores financiados. Adicionalmente foi realizada análise de correlação para avaliar a relação entre crédito rural e crescimento da produção agropecuária. Os resultados do Índice de Gini indicam forte concentração na alocação de recursos. O INCR permitiu identificar um maior número de municípios especializados em atividades agrícolas, principalmente do segmento de agricultura familiar, comparativamente as atividades pecuárias. A análise de correlação identificou que a aplicação de crédito rural está mais fortemente correlacionada com o crescimento da produção animal, principalmente, do rebanho bovino e da produção de ovos de galinha. A correlação com o crescimento da produção agrícola não se mostrou estatisticamente significativa. Conclui-se que a alocação dos recursos da política de crédito rural no Amazonas apresenta forte concentração espacial e setorial e que sua relação com o crescimento da produção tem sido mais evidente no setor pecuário. Espera-se que estes resultados possam ser utilizados no aperfeiçoamento da alocação dos recursos de crédito rural no estado do Amazonas.
\end{abstract}

Palavras-chave: desenvolvimento rural; financiamentos agropecuários; política agrícola.

\section{Evolution of the applications and effects of rural credit policy in the state of Amazonas}

\begin{abstract}
Rural credit plays a fundamental role in economic growth and development, as it is an instrument that enables financial resources for investments in productive infrastructure, costing and commercialization of agricultural production. In this study, the profile and distribution of rural credit resources in the state of Amazonas from 1990 to 2017 was evaluated. We used the database of the Central Bank of Brazil (BACEN) to calculate the Normalized Rural Credit Index (INCR), whose results show the spatial dynamics of the allocation of financing. The Gini Index was estimated to measure the level of concentration in the number of operations and values financed, in addition, correlation analysis was performed to evaluate the relationship between rural credit and growth of agricultural production. The results of the Gini Index indicate a strong concentration in resource allocation. The INCR allowed the identification of a greater number of municipalities specialized in agricultural activities, mainly in the family farming segment, compared to livestock activities. The correlation analysis

\footnotetext{
1 Engenheira Agrônoma, Mestranda em Agronomia pelo Programa de Pós-Graduação em Agronomia (PGAGRO) da Universidade Federal Rural da Amazônia (UFRA). E-mail: carina.madeira@live.com

2 Engenheiro Agrônomo, Doutor, Professor do Programa de Pós-Graduação em Agronomia (PGAGRO) da Universidade Federal Rural da Amazônia (UFRA). E-mail: marcos.marituba@gmail.com.

${ }^{3}$ Economista, Doutor, Professor do Programa de Pós-Graduação em Agronomia (PGAGRO) da Universidade Federal Rural da Amazônia (UFRA). E-mail: fabriciorebello@ hotmail.com

${ }^{4}$ Engenheira Agrônoma, Doutora, Professora do Programa de Pós-Graduação em Agronomia (PGAGRO) da Universidade Federal Rural da Amazônia (UFRA). E-mail: cyntiamei@ hotmail.com.
} 
identified that the application of rural credit is more strongly correlated with the growth of animal production, mainly of cattle herd and chicken egg production. The correlation with the growth of agricultural production was not statistically significant. It is concluded that the allocation of resources of rural credit policy in the Amazon have a strong spatial and sectoral concentration and that its relationship with production growth has been more evident in the livestock sector. It is expected that these results can be used to improve the allocation of rural credit resources in the state of Amazonas.

Keywords: rural development; agricultural finance; agricultural policy.

\section{INTRODUÇÃO}

O desenvolvimento rural é um processo construído gradativamente, a partir de investimentos em ciência e tecnologia, infraestrutura e capital humano. Estes benefícios, quando incorporados aos sistemas de produção agropecuários, oferecem os meios necessários para induzir o aumento da produtividade. Nesta perspectiva, o crédito rural é um dos instrumentos de política agrícola que possui papel fundamental para a redução da pobreza através da geração de emprego e renda nas áreas rurais; atender a demanda por alimentos, ampliada em função da urbanização e do aumento populacional; estimular a conservação dos recursos naturais através do aumento da produtividade das áreas agricultáveis e mutuamente proporcionar o crescimento e o desenvolvimento no campo (REBELLO; SANTOS; SOUZA, 2008).

A extensão rural, pesquisa agropecuária e o crédito rural são políticas agrícolas que contribuem fortemente para a elevação da dimensão socioeconômica da vida no campo. Dentre estes, o crédito destaca-se por exercer um papel fundamental no âmbito da modernização agropecuária, pois disponibiliza os recursos financeiros para investimentos em infraestrutura e aquisição de insumos e maquinários indispensáveis para aumentar a eficiência produtiva (ALVES; CONTINI; GASGUES, 2008; REBELLO; SANTOS; SOUZA, 2008). Para Ramos e Martha Junior (2010), essa política é vista como um dos principais mecanismos de apoio ao setor agropecuário devido a sua dinâmica creditícia ser diferenciada, já que oferece taxas de juros e condições especiais de pagamento aos seus credores.

No Brasil, a consolidação das bases legais para os financiamentos de crédito rural ocorreu a partir de 1965, quando o governo federal instituiu, por meio da Lei $\mathrm{n}^{\circ} 4.289$, o Sistema Nacional de Crédito Rural (SNCR) com os objetivos de (i) financiar parte dos custos de produção agrícola; (ii) estimular a formação de capital; (iii) acelerar a adoção de novas tecnologias; e, (iv) fortalecer a posição econômica dos produtores, especialmente pequenos e 
médios (CASTRO, 2017; LOPES; LOWERY; PEROBA, 2016; RAMOS; MARTHA JUNIOR, 2010).

No Brasil, historicamente, o crédito rural esteve relacionado a programas e recursos governamentais, a exemplo do Banco do Brasil, aos Bancos de fomento regional (Banco da Amazônia e Banco do Nordeste) e as linhas especiais de financiamento do BNDES, principal responsável pela concessão de créditos de longo prazo (CASTRO, 2017), o que acaba restringindo a massa de recursos disponibilizados ao público.

Outro problema que dificulta o pleno fornecimento de crédito no Brasil é a restrição de acesso aos recursos financeiros. Sobre isso, Souza, Ney e Ponciano (2015) apontam que esta dificuldade é percebida, sobretudo, quando pequenos produtores disputam recursos de crédito com os grandes produtores, uma vez que os pequenos acabam saindo em desvantagem por conta da falta de garantias e por apresentarem maiores riscos de inadimplência para os bancos.

Com o intuito de fazer uma redistribuição mais efetiva dos recursos para os pequenos agricultores, em 1996, foi criado o Programa Nacional de Fortalecimento da Agricultura Familiar (PRONAF). Apesar dessa inciativa, vários estudos (ARAUJO; VIEIRA FILHO, 2018; SOUZA; BARBÉ, 2014; SOUZA; NEY; PONCIANO, 2015) mostram que ainda há uma tendência de concentração dos recursos nas regiões Sul e Sudeste do País em detrimento de outras.

Tendo em vista que a concentração dos recursos é um dos principais problemas da política de crédito rural no Brasil, pois deixa de cumprir com a função de ofertar recursos financeiros ao setor produtivo, principalmente nas regiões mais descapitalizadas, com vistas a alavancar o desenvolvimento rural, torna-se necessário realizar estudos para avaliar a efetividade dessa política, principalmente quanto à alocação distributiva dos recursos.

Nesta linha temática, o trabalho de Souza et al. (2018) avalia a distribuição dos recursos de crédito rural no Brasil entre 2007 e 2017 e aponta os estados do Rio Grande do Sul, São Paulo, Minas Gerais e Paraná como maiores centralizadores de recursos neste período. Contrariamente, os estados com menores participações correspondem ao Amapá, Roraima, Amazonas e Distrito Federal.

De acordo com estes resultados, cabe destaque ao estado do Amazonas em função do baixo nível de alocação de recursos de crédito rural e cujo perfil agropecuário ainda não consegue atender as necessidades básicas do mercado local na maioria dos produtos alimentícios, embora tenha possibilidades de contribuir para a segurança alimentar da região 
através de cultivos de ciclo curto no segmento familiar, e ainda, subsidiar a pesca comercial da região através de suas áreas de várzea (SANTOS; PEREIRA, 2020).

Assim, partindo do entendimento que o Amazonas possui boas aptidões para buscar a diversidade produtiva da economia, superar a dependência da Zona Franca de Manaus e criar novas oportunidades fora desse circuito, o objetivo deste estudo foi avaliar a distribuição espacial e concentração do crédito rural no estado do Amazonas no período de 1990 a 2017. O montante de recursos do crédito rural também foi correlacionado com o perfil da produção agropecuária amazonense, com o intuito de verificar a relação entre crédito rural e o crescimento da produção agropecuária.

\section{METODOLOGIA}

\section{1 Área de estudo}

O estado do Amazonas dispõe da maior superfície territorial entre os estados da federação brasileira, possuindo $1.559 .146,876 \mathrm{~km}^{2}$. Sua população estimada, em 2019, foi de 4.114.597 habitantes (IBGE, 2020). O estado conta com 62 municípios, sendo que a capital, o município de Manaus, abriga 53,0\% da população (IBGE, 2020). No aspecto social, as condições básicas de saúde, educação e renda mensuradas pelo índice de Desenvolvimento Humano (IDH) mostra que a proporção do desenvolvimento nesta unidade da federação é mediana $(0,674)$ (PNUD, 2010).

O padrão local de desenvolvimento econômico é altamente dependente do Distrito Industrial, onde as atividades se concentram no Polo Industrial de Manaus (PIM) que é destaque na produção de aparelhos eletrônicos como televisores, eletrodomésticos e celulares. Entretanto, mesmo sendo considerada uma região com forte viés industrial, também existem na localidade algumas iniciativas na produção de alimentos, agroindústrias, piscicultura, beneficiamento de madeira e outros, porém todos com baixo desempenho produtivo (SANTOS; FRANÇA, 2018).

\subsection{Fonte de dados}

Para o desenvolvimento desta pesquisa foram consultadas diversas fontes de dados sobre a produção agropecuária, dentre eles, o Sistema IBGE de Recuperação Automática SIDRA do Instituto Brasileiro de Geografia e Estatística (IBGE, 2018a; IBGE, 2018b) para 
averiguar o comportamento do setor produtivo no estado do Amazonas. A partir dessa base de dados, foram extraídas séries temporais de área colhida, quantidade produzida, produtividade para as principais lavouras temporárias e permanentes. Na caracterização da pecuária, foram obtidas séries temporais contendo informações relacionadas ao efetivo dos rebanhos, plantel de vacas ordenhadas e produtos de origem animal.

De posse dessas informações, utilizou-se o método de Regressão Linear Simples para calcular a Taxa Geométrica de Crescimento e avaliar o padrão de crescimento da produção agropecuária, analisando o quanto das variações na produção podem ser atribuídas ao incremento de área colhida (efeito-área) e melhorias na produtividade (efeito-rendimento) para as abordagens relacionadas à agricultura. Em relação à pecuária, o método captou variações na produção provenientes de alterações no efetivo dos rebanhos e na escala de produção de produtos de origem animal através do chamado efeito-expansão.

A utilização desta metodologia é bastante recorrente em pesquisas que avaliam os padrões de crescimento da produção agrícola. O modelo é especificado da seguinte forma (NEGRI NETO; COELHO; MOREIRA, 1993):

$$
Y_{t}=a+b X+e
$$

Em que:

$Y_{t}=$ Logarítmo natural da variável;

$a=$ Logarítmo natural de A;

$b=$ Logarítmo natural da taxa geométrica de crescimento $(1+\mathrm{i})$;

$X=\mathrm{t}$ : É uma variável de tendência; e

$e=$ É o termo de erro aleatório.

As informações relacionadas ao crédito foram obtidas junto ao Anuário Estatístico de Crédito Rural e da Matriz de Dados do Crédito Rural, ambos disponíveis no sistema de informação do Banco Central do Brasil (BACEN, 2018).

Para efeito de análises das variáveis monetárias foi realizada a deflação dos preços a partir da utilização do Índice Geral de Preços Disponibilidade Interna (IGP-DI) da Fundação Getúlio Vargas (FGV, 2018), tendo como base a média do ano de 2017.

Com vistas a obter a classificação e espacialização dos municípios amazonenses de acordo com a principal atividade financiada, calculou-se o Índice Normalizado de Crédito 
Rural (INCR), de acordo com a seguinte fórmula (NASCIMENTO; SANTOS; ALMEIDA, 2011; SANTOS; REBELLO; SANTANA, 2012):

Em que:

$$
I N C R_{i}=\frac{C A_{i}-C P_{i}}{C A_{i}+C P_{i}}
$$

$I N C R_{i}=$ Índice normalizado das aplicações de crédito rural do i-ésimo município do estado do Amazonas;

$C A_{i}=$ Valor das operações de crédito aplicado na atividade agrícola no i-ésimo município do estado do Amazonas;

$C P_{i}=$ Valor das operações de crédito aplicado na atividade pecuária no i-ésimo município do estado do Amazonas.

Os valores do INCR variam entre -1 e 1 . Os municípios foram classificados em pecuaristas $(-1 \leq \operatorname{INCR}<-0,5)$; medianamente pecuaristas $(-0,5 \leq \operatorname{INCR}<0,0)$; medianamente agrícolas $(0,0 \leq \mathrm{INCR}<0,5)$ e agrícolas $(0,5 \leq \mathrm{INCR} \leq 1,0)$. A partir das classificações obtidas, foi elaborado um mapa do Amazonas em escala municipal utilizando o programa QGis.

Para aferir o nível de concentração das aplicações de crédito rural utilizou-se o Índice de Gini (HOFFMAN, 1991), calculado por meio da seguinte fórmula:

$$
G=1-\sum_{k=0}^{k=n-1}\left(X_{k+1}-X_{k}\right)\left(Y_{k+1}+Y_{k}\right)
$$

Em que:

$\mathrm{G}=$ índice de Gini;

$\mathrm{X}_{\mathrm{k}}=$ proporção acumulada do número de municípios do estado do Amazonas até o grupo k;

$\mathrm{Y}_{\mathrm{k}}=$ proporção acumulada de crédito rural liberado até o grupo k;

$\mathrm{n}=$ número total de municípios.

A concepção interpretativa do índice de Gini é de que quanto mais próximo de 1, maior o nível de concentração da distribuição da variável, no caso, aplicação de crédito rural. 
A análise de correlação de Pearson foi empregada neste trabalho com o intuito de verificar o nível de associação entre as variáveis crédito agrícola e as principais lavouras temporárias e permanentes. Da mesma forma foram correlacionados o crédito pecuário e as variáveis efetivo do rebanho bovino, galináceo, plantel de vacas ordenhadas, produção de leite e ovos.

Uma correlação positiva indica que as variáveis evoluem no mesmo sentido. De modo inverso acontece com os resultados negativos, pois indicam que as variáveis evoluem em sentidos opostos. Estas análises foram realizadas por meio do software econométrico GRETL (FSF, 2018).

\section{RESULTADOS E DISCUSSÃO}

Nos últimos anos, a agropecuária brasileira passou por mudanças significativas ocasionadas pela incorporação de novas tecnologias às atividades produtivas. Estas, por sua vez, possibilitaram o aumento da produtividade da terra, trabalho e capital. Nessa perspectiva, os avanços em pesquisa contribuíram para o desenvolvimento de cultivares mais adaptadas, insumos eficientes para correção do solo e maquinário de ponta (ALVES; CONTINI; GASQUES, 2008).

A produção agropecuária ainda possui baixa participação relativa na economia do Amazonas, fazendo com que o estado ocupe a $5^{\mathrm{a}}$ posição no ranking de participação, considerando os sete estados da região Norte. Tais resultados não chegam a surpreender, uma vez que o setor industrial de Manaus atua fortemente em seu dinamismo econômico (OLIVEIRA et al., 2017), ou ainda como observa Benchimol (1977), em clássico estudo sobre a realidade do Estado, ao destacar que o seu cenário produtivo, e mais especificamente no município de Manaus, sofre grandes influências do ciclo das águas e o movimento das águas do Rio Negro, que incitam a ocorrência de enchentes. Estas intempéries provocam um rápido aumento no preço de produtos alimentares como farinha, leite e verduras devido aos regimes de cheias e vazantes dos rios (BENCHIMOL, 1977). Havendo, portanto, uma dificuldade natural em manter certa estabilidade nas atividades de produção agropecuária. Isso, no entanto, com uma gestão eficiente dos instrumentos de política agrícola e conhecimento tecnológico pode ser revertido em benefício para dotar o setor agropecuário de eficiência produtiva em determinadas atividades-chave. 
Na próxima seção analisam-se aspectos relacionados ao comportamento da produção agropecuária no Amazonas, contemplando as principais culturas produzidas no estado bem como os rebanhos e produtos de origem animal que tiveram destaque entre os anos de 1990 a 2017. Para melhor interpretação das análises este período foi segmentado em três subperíodos (1990-2000; 2000-2010 e 2010-2017). A finalidade desta abordagem buscou compreender as principais mudanças ocorridas no cenário produtivo ao longo dos anos.

\subsection{COMPORTAMENTO DA AGRICULTURA E PECUÁRIA NO AMAZONAS}

\section{1. 1 Agricultura}

As taxas de crescimento das variáveis relacionadas a produção agrícola amazonense são apresentadas na Tabela 1. Analisando estes resultados em períodos distintos, é possível observar certos padrões no comportamento geral da atividade agrícola no Estado.

Tabela 1 - Taxas de crescimento da área colhida, produção e produtividade referente às principais lavouras temporárias e permanentes no estado do Amazonas, 1990-2017.

\begin{tabular}{|c|c|c|c|c|c|c|c|c|c|}
\hline \multirow{2}{*}{ Culturas } & \multicolumn{3}{|c|}{$\begin{array}{l}\text { Área Colhida } \\
\text { (efeito-área) }\end{array}$} & \multicolumn{3}{|c|}{ Produção } & \multicolumn{3}{|c|}{$\begin{array}{c}\text { Produtividade } \\
\text { (efeito-rendimento) }\end{array}$} \\
\hline & $\begin{array}{l}1990- \\
2000 \\
\end{array}$ & $\begin{array}{c}2000- \\
2010 \\
\end{array}$ & $\begin{array}{l}2010- \\
2017 \\
\end{array}$ & $\begin{array}{l}1990- \\
2000 \\
\end{array}$ & $\begin{array}{c}2000- \\
2010 \\
\end{array}$ & $\begin{array}{l}2010- \\
2017 \\
\end{array}$ & $\begin{array}{l}1990- \\
2000 \\
\end{array}$ & $\begin{array}{c}2000- \\
2010 \\
\end{array}$ & $\begin{array}{l}2010- \\
2017 \\
\end{array}$ \\
\hline Abacaxi & $35,6 \%$ & $-1,4 \%$ & $2,2 \%$ & $20,3 \%$ & $12,4 \%$ & $7,4 \%$ & $-11,3 \%$ & $14,0 \%$ & $5,1 \%$ \\
\hline Arroz & $24,1 \%$ & $-13,8 \%$ & $-34,7 \%$ & $31,3 \%$ & $-14,1 \%$ & $-33,2 \%$ & $5,8 \%$ & $-0,4 \%$ & $2,3 \%$ \\
\hline Banana & $36,0 \%$ & $-14,0 \%$ & $-0,6 \%$ & $37,7 \%$ & $-1,8 \%$ & $1,7 \%$ & $1,3 \%$ & $14,2 \%$ & $2,3 \%$ \\
\hline Cacau & $4,1 \%$ & $1,0 \%$ & $-28,2 \%$ & $19,9 \%$ & $3,6 \%$ & $-23,0 \%$ & $15,2 \%$ & $2,6 \%$ & $7,3 \%$ \\
\hline Cana-de-açúcar & $4,6 \%$ & $4,9 \%$ & $-4,9 \%$ & $5,9 \%$ & $6,0 \%$ & $-5,4 \%$ & $1,2 \%$ & $1,1 \%$ & $-0,5 \%$ \\
\hline Guaraná & $5,3 \%$ & $2,2 \%$ & $3,4 \%$ & $18,1 \%$ & $4,4 \%$ & $-0,6 \%$ & $12,1 \%$ & $2,1 \%$ & $-3,8 \%$ \\
\hline Laranja & $8,4 \%$ & $-0,1 \%$ & $3,8 \%$ & $4,3 \%$ & $-6,7 \%$ & $5,1 \%$ & $-3,7 \%$ & $-6,7 \%$ & $1,3 \%$ \\
\hline Malva & $-5,5 \%$ & $12,6 \%$ & $-22,5 \%$ & $-4,2 \%$ & $11,4 \%$ & $-23,8 \%$ & $1,3 \%$ & $-1,1 \%$ & $-1,8 \%$ \\
\hline Mamão & $49,5 \%$ & $-8,7 \%$ & $9,4 \%$ & $45,2 \%$ & $-0,6 \%$ & $8,5 \%$ & $-2,9 \%$ & $8,9 \%$ & $-0,9 \%$ \\
\hline Mandioca & $14,8 \%$ & $-1,4 \%$ & $1,0 \%$ & $11,6 \%$ & $-0,6 \%$ & $0,9 \%$ & $-2,8 \%$ & $0,9 \%$ & $-0,1 \%$ \\
\hline Maracujá & $22,5 \%$ & $7,0 \%$ & $5,5 \%$ & $40,7 \%$ & $3,2 \%$ & $5,8 \%$ & $14,8 \%$ & $-3,6 \%$ & $0,3 \%$ \\
\hline Melancia & $23,0 \%$ & $-0,7 \%$ & $-3,2 \%$ & $15,8 \%$ & $18,7 \%$ & $-3,6 \%$ & $-5,8 \%$ & $19,5 \%$ & $-0,4 \%$ \\
\hline Milho & $16,9 \%$ & $2,6 \%$ & $-20,8 \%$ & $13,0 \%$ & $8,6 \%$ & $-19,9 \%$ & $-3,3 \%$ & $5,9 \%$ & $1,1 \%$ \\
\hline
\end{tabular}

Fonte: IBGE (2018a).

i) 1990-2000: neste período praticamente todas as culturas, com exceção da malva, apresentaram crescimentos positivos em relação ao efeito-área, indicando que neste momento muitas culturas estavam em expansão no Estado. O comportamento da produção, por sua vez, acompanhou essa mesma tendência para todas as culturas, indicando certo equilíbrio entre as 
variáveis. Contudo, ao se analisar o efeito-rendimento (produtividade) pode-se inferir que a maioria dos cultivos (arroz, banana, cana-de-açúcar e malva) não conseguiram obter ganhos expressivos em produtividade. Algumas produções (abacaxi, laranja, mamão, mandioca, melancia e milho), inclusive, apresentaram redução de rendimento, sinalizando para uma situação em que a expansão destas atividades foi dada única e exclusivamente pela incorporação de novas áreas. Neste cenário, as únicas atividades produtivas que apresentaram bons rendimentos, e, portanto, foram eficazes em manter o equilíbrio entre todas as variáveis analisadas, foram cacau, guaraná e maracujá.

ii) 2000-2010: este intervalo contrasta com o período anterior, pois muitas culturas tiveram aumentos pouco expressivos, ou mesmo declinaram, nas suas áreas de cultivo. As reduções mais drásticas foram percebidas nos plantios de arroz e banana. Da mesma forma, os maiores incrementos foram observados nos cultivos de malva e maracujá. No que diz respeito a produção, os plantios de melancia, abacaxi e malva obtiveram os melhores resultados. Já o cultivo de arroz apresentou o pior desempenho neste segmento. Analisando os rendimentos das culturas, novamente foi observado que muitas atividades mantiveram um baixo desempenho, pois os cultivos de melancia, banana, abacaxi e mamão foram as únicas mais eficientes no aumento da produção em menor área.

iii) 2010-2017: Similar a década anterior, algumas culturas permaneceram estáveis e outras reduziram suas áreas de cultivo. A reduções mais aparentes dizem respeito aos plantios de arroz, cacau, malva e milho. O comportamento da produção seguiu essa mesma tendência de estagnação e retração, esta última evidenciada pelos mesmos plantios citados anteriormente. O rendimento manteve, de modo geral, o mesmo desempenho insatisfatório observado nos períodos anteriores. Dessa vez, a produção de guaraná foi a que apresentou pior resultado. Já as culturas do cacau e abacaxi exibiram as elevações mais aparentes.

A compreensão destes resultados dá indícios sobre quais atividades são, ou não, mais praticadas na agricultura local. O cultivo de grãos, por exemplo, não é tradicional na região pois está muito associado ao autoconsumo e pequena comercialização do excedente no segmento familiar (SEDECTI, 2016).

O maracujá por sua vez, foi uma atividade que muito se desenvolveu no período 19902000 e nos anos seguintes (2000-2010 e 2010-2017), reduziu seu desempenho produtivo. A nível territorial, a produção de maracujá se destaca no município de Manacapuru.

As culturas da laranja, mamão, mandioca, melancia, cana-de-açúcar e guaraná oscilaram seus resultados em todas as variáveis nos três períodos analisados. Isso mostra que 
ao longo dos anos, embora tenham tido algumas flutuações no mercado, os produtores locais continuaram se dedicando ao cultivo destas culturas.

Contudo, vale ressaltar que diferentemente da maioria dos produtos agropecuários produzidos no estado, o setor agroindustrial é responsável pela maior parte da produção de cana e por isso uma parcela considerável da produção se concentra no município de Presidente Figueiredo (ALMUDI; PINHEIRO, 2015), local onde se faz presente a Usina Jayoro especializada na produção cana-de-açúcar, álcool, biodiesel e guaraná (RESENDE; ORLANDO FILHO, 2017).

Entretanto, ainda que o guaraná tenha apoio do setor agroindustrial é necessário dedicar maior atenção para o modo como vem sendo desenvolvida essa atividade na região, pois atualmente vem perdendo espaço para o estado da Bahia que desde o ano 2000 ocupa a primeira posição no ranking de produção desta cultura (IBGE, 2018a). Tal informação oferece um importante indicativo para os estados da região amazônica quanto à preemência de realizar investimentos estratégicos na geração de conhecimento e agregação de valor às atividades tradicionais da região sobre pena de se perder sua vantagem comparativa. A história da região está repleta de exemplos nessa linha (HOMMA, 2014; REBELLO; HOMMA, 2017;).

A situação da malva, por sua vez, reflete o comportamento de uma atividade que foi muito importante no passado e aos poucos perdeu espaço na economia do estado por conta de ser uma atividade muito rudimentar, carente de pesquisas no âmbito tecnológico e com políticas públicas pouco abrangentes, além de uma baixa organização por parte dos produtores (ARAÚJO; PEREIRA, 2017).

As produções de cacau e banana, por sua vez, foram as únicas que apresentaram rendimentos positivos em todos os períodos observados. Apesar deste resultado satisfatório, ambas passaram por momentos de flutuações. Estes resultados evidenciam certa fragilidade, pois similarmente ao que ocorre com outras culturas no estado, as intempéries ambientais relacionadas, principalmente as cheias da região, acabam por dificultar a produção e reduzir a confiança dos produtores em investir nestas atividades, tendo em vista que não são raros os casos em que plantios são dizimados pela ocorrência de cheias (FERNANDES, 2016).

O estudo de Meneghetti e Souza (2015) relata sobre alguns elementos essenciais para contornar estas dificuldades regionais, alegando que a região necessita de uma estrutura própria para a transferência de tecnologia e extensão; organização; produção e logística, onde seja possível aliar a visão de saberes locais, à visão dos técnicos e pesquisadores. 


\section{1. 2 Pecuária}

A produção de carne na Amazônia atende grande parte das demandas comerciais internas do País. Em termos percentuais, cerca de $90 \%$ da carne produzida na região é consumida em escala nacional, e destes, aproximadamente $70 \%$ se destinam a regiões onde a economia é mais dinâmica (Sul e Sudeste). Esta alta demanda nacional e internacional aliada ao crescimento econômico nos países de baixa renda, são fatores que direcionam o avanço da pecuária para novas regiões (NEPSTAD et al., 2006). Logo, é neste cenário que a pecuária da região Norte é vista como promissora no desenvolvimento desta cadeia de produção, desde que altere sua relação de produtividade para não impactar na expansão de área.

Os rebanhos mais representativos do Amazonas são galináceos e bovinos. Ao todo, o rebanho bovino soma 1.343 .574 cabeças. Um número muito pequeno se comparado aos demais estados da região Norte, onde ocupa a $6^{\text {a }}$ posição com participação de apenas $2,7 \%$ no rebanho total (IBGE, 2018b). Este efetivo bovino se concentra em municípios que fazem fronteira com os estados do Acre, Rondônia, Mato Grosso e Pará, localizados mais precisamente ao Sul Amazonense (SEDECTI, 2016).

No caso da pecuária leiteira, o Norte do País participa com apenas 6,5\% da produção nacional. Em dados brutos, este valor corresponde a 2,1 bilhões de litros. A produção no Amazonas foi de 43 milhões de litros, em 2017, conferindo ao estado uma participação equivalente a $2 \%$ do total na região Norte (IBGE, 2018b). De acordo com Silva e Carrero (2018), esse baixo desempenho é explicado pela composição da bacia leiteira do estado, cuja formação engloba, principalmente, gado leiteiro de baixa produtividade.

A produção avícola no Amazonas é bastante praticada no segmento de postura. A avicultura de corte, por outro lado, é incipiente e suas lacunas sãos preenchidas pela avicultura caipira, que se destaca pelos contextos sociais e agroecológicos associados a este sistema de manejo (CRUZ et al., 2016).

No contexto da região Norte, o efetivo de rebanho galináceo do Amazonas classificase em $4^{\circ}$ lugar no ranking, ficando atrás dos estados do Pará, Tocantins e Rondônia (IBGE, 2018b). Em 2017, o estado possuía 3.915 .586 bicos de galinhas, frangos e pintos. O município líder neste ramo é Manaus, que apresentou 2.064.500 bicos, correspondendo a 52\% do efetivo total do estado. 
As taxas de crescimento para a pecuária e produtos de origem animal são descritos na Tabela 2. Hierarquicamente, entre 1990-2000, os resultados mostram maior expansão para os rebanhos ovino, bubalino, suíno, bovino e galináceo, cujas taxas de crescimento foram 11,2\%, $5,6 \%, 3,5 \%, 3,0 \%$ e $-1,2 \%$ ao ano, respectivamente. Na década seguinte (2000-2010), as criações de ovinos e suínos perderam espaço.

A primeira devido à falta de técnicas de manejo e infraestrutura de abatedouros apropriados (OLIVEIRA et al., 2017), e a segunda, provavelmente em razão da carne não ter uma aceitabilidade capaz de estimular a criação suína. Já nos períodos mais recentes (20102017), a quase totalidade dessas atividades sofreram retrações, com exceção da bubalinocultura, que exibiu taxa de crescimento de apenas $1,1 \%$ ao ano.

Tabela 2 - Taxas de crescimento dos rebanhos e produtos de origem animal no estado do Amazonas, 1990-2017.

\begin{tabular}{lrrr}
\hline \multirow{2}{*}{ Efetivo dos rebanhos } & \multicolumn{3}{c}{ Taxa de crescimento - Efeito-expansão (\% ao ano) } \\
\cline { 2 - 4 } & $1990-2000$ & $2000-2010$ & $2010-2017$ \\
\hline Galináceo & $-1,2 \%$ & $3,2 \%$ & $-0,2 \%$ \\
Bovino & $3,0 \%$ & $5,2 \%$ & $-1,1 \%$ \\
Bubalino & $5,6 \%$ & $3,3 \%$ & $1,1 \%$ \\
Suíno & $3,5 \%$ & $-10,7 \%$ & $-4,8 \%$ \\
Ovino & $11,2 \%$ & $-2,6 \%$ & $-6,7 \%$ \\
Vacas Ordenhadas (cabeças) & $2,1 \%$ & $3,0 \%$ & $-3,4 \%$ \\
Produtos de origem animal & & & \\
Ovos de galinha (mil dúzias) & $4,8 \%$ & $15,6 \%$ & $-4,5 \%$ \\
Leite (mil litros) & $-1,3 \%$ & $0,3 \%$ & $-1,5 \%$ \\
Mel de abelha (quilogramas) & $-25,1 \%$ & $55,0 \%$ & $-5,9 \%$ \\
\hline Fo
\end{tabular}

Fonte: IBGE (2018b).

O número de vacas ordenhadas também cresceu positivamente nas duas primeiras décadas (1990-2000 e 2000-2010), onde apresentou elevações de 2,1\% e 3,0\% ao ano, respectivamente. Já entre 2010 e 2017 a atividade retraiu em -3,4\% a.a.

Sobre o desenvolvimento desta atividade ressalta-se que, apesar dos resultados positivos nas primeiras décadas, a visão geral da pecuária ainda está muito distante da realidade de outros estados mesmo na região Norte, onde os estados de Rondônia e Pará são os mais destacados na atividade. 
Se tratando dos produtos de origem animal, a produção de ovos foi a única que se expandiu entre 1990 e 2000. Nesse momento, a retração mais acentuada esteve a cargo da produção de mel (-25,1\% a.a.) e, em menor proporção, na produção de leite (-1,3\% a.a).

Tal situação foi revertida entre 2000 e 2010, pois as atividades ligadas à criação de abelhas para a produção de mel expandiram 55,0\% a.a. por efeito da maior presença de grupos de pesquisas em abelhas atendendo comunidades de Manaus para dar capacitação teórica e prática em meliponicultura, conforme apontado por Vilas Boas (2012).

Ainda entre os anos 2000 e 2010 a produção de ovos aumentou em 15,6\% a.a. por conta da expansão do setor avícola de postura e caipira na região. Por outro lado, novamente a produção de leite se manteve constante no período considerado.

Por último, entre 2010 e 2017 todos os produtos de origem animal retraíram suas produções, similarmente ao que ocorreu com o efetivo de rebanhos. A produção de mel e ovos recuou em $-5,9 \%$ e $-4,5 \%$ ao ano, respectivamente. Já o decréscimo (-1,5\% a.a.) para o leite foi algo esperado, pois em todos os períodos a atividade manteve um baixo desempenho em decorrência de a pecuária leiteira ser bastante incipiente.

\section{2 Evolução dos financiamentos agropecuários}

Considerando o período de 1990 a 2017, foram contratadas 206.202 operações de crédito rural, movimentando cerca de $\mathrm{R} \$ 4$ bilhões. $\mathrm{O}$ setor pecuário foi o que mais se beneficiou do uso de crédito, sendo alocado cerca de $\mathrm{R} \$ 2,1$ bilhões, o que correspondeu a $52,51 \%$ do volume total de crédito concedido. Nas atividades agrícolas foi alocado $\mathrm{R} \$ 1,9$ bilhão, representando 47,49\% do total financiado. Os anos que ocorreram os maiores valores financiados de crédito foram 2001 (R \$ 355 milhões), 2012 ( $\mathrm{R}$ \$ 286 milhões) e 2014 (R \$ 246 milhões).

A Figura 1 mostra o comportamento irregular na distribuição do valor das contratações. No período em que se observou maior pico (2001), constata-se que as aplicações de crédito voltados para a pecuária se sobressaíram.

Em 1999, o crédito agrícola contribuiu com cerca de $56,81 \%$ e a pecuária com 43,19\%. Nos anos 2000 houve uma inversão, onde 75,75\% das aplicações foram direcionadas a pecuária e apenas $24,25 \%$ destinados à agricultura. 
Nos anos seguintes, se manteve o mesmo comportamento, em que a maior parte da destinação de créditos se deu para o financiamento pecuário.

Figura 1 - Evolução do valor das contratações de crédito rural (agrícola e pecuário) no estado do Amazonas, 1990-2017.

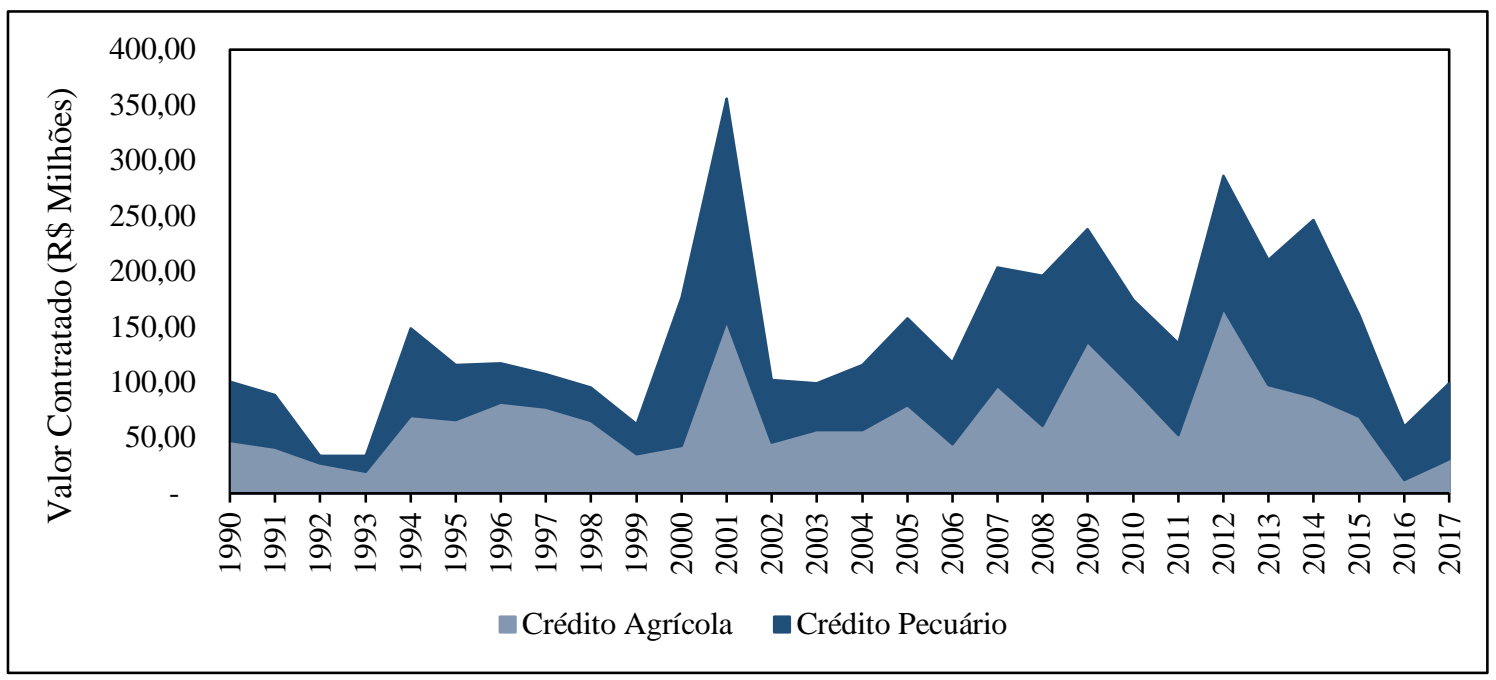

Fonte: Banco Central do Brasil (BACEN, 2018).

Nota: Valores corrigidos para R\$ Mil (Base: média geral do ano de 2017) pelo IGP-DI (FGV, 2018).

Essa diminuição no financiamento agrícola pode ser explicada, em parte, pelas quedas de produção percebidas em várias culturas, cuja causa esteve relacionada, principalmente, a fatores bióticos e abióticos como a ocorrência de pragas e doenças e períodos de cheias e estiagens, que dificultou a produção de culturas tais como a banana e o cacau, por exemplo, e afetou a confiança dos produtores em voltar a investir nestas atividades (FERNANDES, 2016).

Na Figura 2, é mostrada a evolução do valor médio das operações de crédito agrícola e pecuário. Ao longo desta série, foram percebidos resultados similares a evolução dos volumes de crédito contratado.

De modo que os valores médios das operações estiveram mais relacionados ao financiamento pecuário, cujo ápice foi atingido no ano de 2001 ( $\mathrm{R} \$ 840.686,59)$, enquanto que o valor médio das operações destinadas ao financiamento agrícola se manteve relativamente estável ao longo dos anos. 
Figura 2 - Evolução do valor médio das operações de crédito rural (agrícola e pecuário) no estado do Amazonas, 1990-2017.

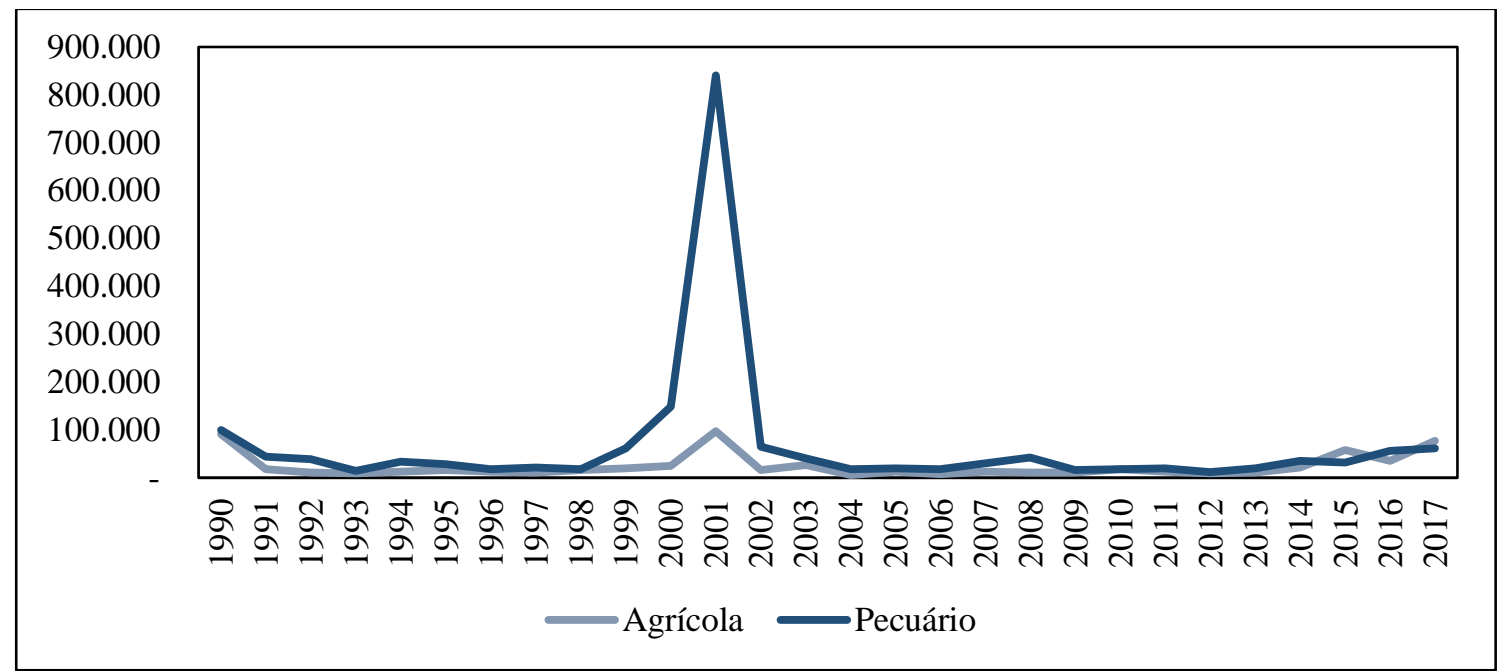

Fonte: Banco Central do Brasil (BACEN, 2018).

Nota: Valores corrigidos para R\$ Mil (Base: média geral do ano de 2017) pelo IGP-DI (FGV, 2018).

Analisando o comportamento da evolução do crédito rural no Brasil, o estudo de Sousa et al. (2020) relata que a partir dos anos 2000 houve a predominância da atividade pecuária nos financiamentos da região Norte, movimento este que se repetiu por todo o país a partir da estabilização da moeda (1994) e o aumento das exportações de produtos pecuários. Sendo assim, pode-se dizer que o pico do valor médio das operações de crédito pecuário no Amazonas (2001) possivelmente está associado ao maior impulso desta atividade em nível nacional neste período.

A soma dos contratos destinados a agricultura e pecuária nos anos de 1990-2017, correspondeu a 132.483 e 73.719 operações, respectivamente. Relacionando estas informações com o volume de recursos que foram destinados a cada uma destas atividades, é possível perceber que há uma tendência de concentração do crédito em contratos de alto valor para a pecuária, pois esta participou em menor proporção do número de operações e ainda assim obteve altos valores financiados.

Os três municípios que mais receberam recursos de crédito rural foram São Paulo de Olivença ( $\mathrm{R}$ \$ 891,44 milhões), Itacoatiara ( $\mathrm{R}$ \$ 396,40 milhões) e Manaus ( $\mathrm{R}$ \$ 294,88 milhões), correspondendo a 22,12\%, 9,84\% e 7,32\% do total de recursos alocados no estado. Da mesma forma, o município que menos obteve crédito foi Santa Isabel do Rio Negro, com R\$ 0,81 milhão $(0,02 \%)$. 
Considerando apenas o crédito agrícola, São Paulo de Olivença foi o município que mais se destacou neste segmento, captando um volume de $\mathrm{R} \$ 433,85$ milhões, que correspondeu a 22,65\% dos recursos alocados em agricultura. Comparativamente, o município de menor participação nesse tipo de financiamento foi Santa Isabel do Rio Negro, somando apenas $\mathrm{R}$ \$ 0,34 milhão com participação de 0,02\%, sendo, portanto, o município com pior desempenho na alocação de recursos.

Fazendo a mesma análise para a atividade pecuária, os resultados mostraram que novamente o município São Paulo de Olivença captou o maior volume de crédito, absorvendo $\mathrm{R} \$ 457,59$ milhões, que equivaleu a 21,64\% dos recursos alocados em pecuária.

Os municípios mais destacados na alocação de crédito, não por acaso, apresentam peculiaridades produtivas e/ou infraestruturais. São Paulo de Olivença, por exemplo, se caracteriza pela prática da agricultura familiar, criação de animais de pequeno porte e uma boa estrutura de mercado para pesca-caça (SCHOR, 2017). Itacoatiara, por sua vez, conta com a presença de um Terminal Privativo Misto ao qual serve de base para escoamento de grãos (SCHOR; MARINHO, 2013). Manaus, principal centro financeiro, possui uma economia fundamentada nos setores industrial e extrativo (RODRIGUES, 2016).

Já em Santa Isabel do Rio Negro, região menos favorecida com os recursos de crédito, prevalecem as atividades agrícolas e pesqueiras. A primeira centrada basicamente na produção de mandioca, e a segunda, com problemas de escassez do pescado (EMPERAIRE; ELOY, 2008; SILVA, 2011).

A análise do INCR permitiu identificar em quais municípios as operações de crédito convergiram mais para a pecuária ou agricultura. De modo geral, a dinâmica do estado mostra que existe uma boa demanda por crédito agrícola, tendo em vista que de acordo com a classificação do INCR, 11 municípios foram classificados como Agrícolas, 26 Medianamente Agrícolas, 7 Pecuaristas e 18 municípios Medianamente Pecuaristas (Figura 3).

Contudo, tendo em vista que o estado aloca maior quantia de crédito em atividades pecuárias, o entendimento da performance de aplicação do crédito rural no Amazonas sinaliza para uma situação onde há poucos municípios concentrando a maior parcela de recursos para serem aplicados na produção animal, ao mesmo tempo em que, vários municípios tomam crédito a baixos valores de operações para financiar a produção agrícola. 
Figura 3 - Índice Normalizado de Crédito Rural no estado do Amazonas, 1990-2017.

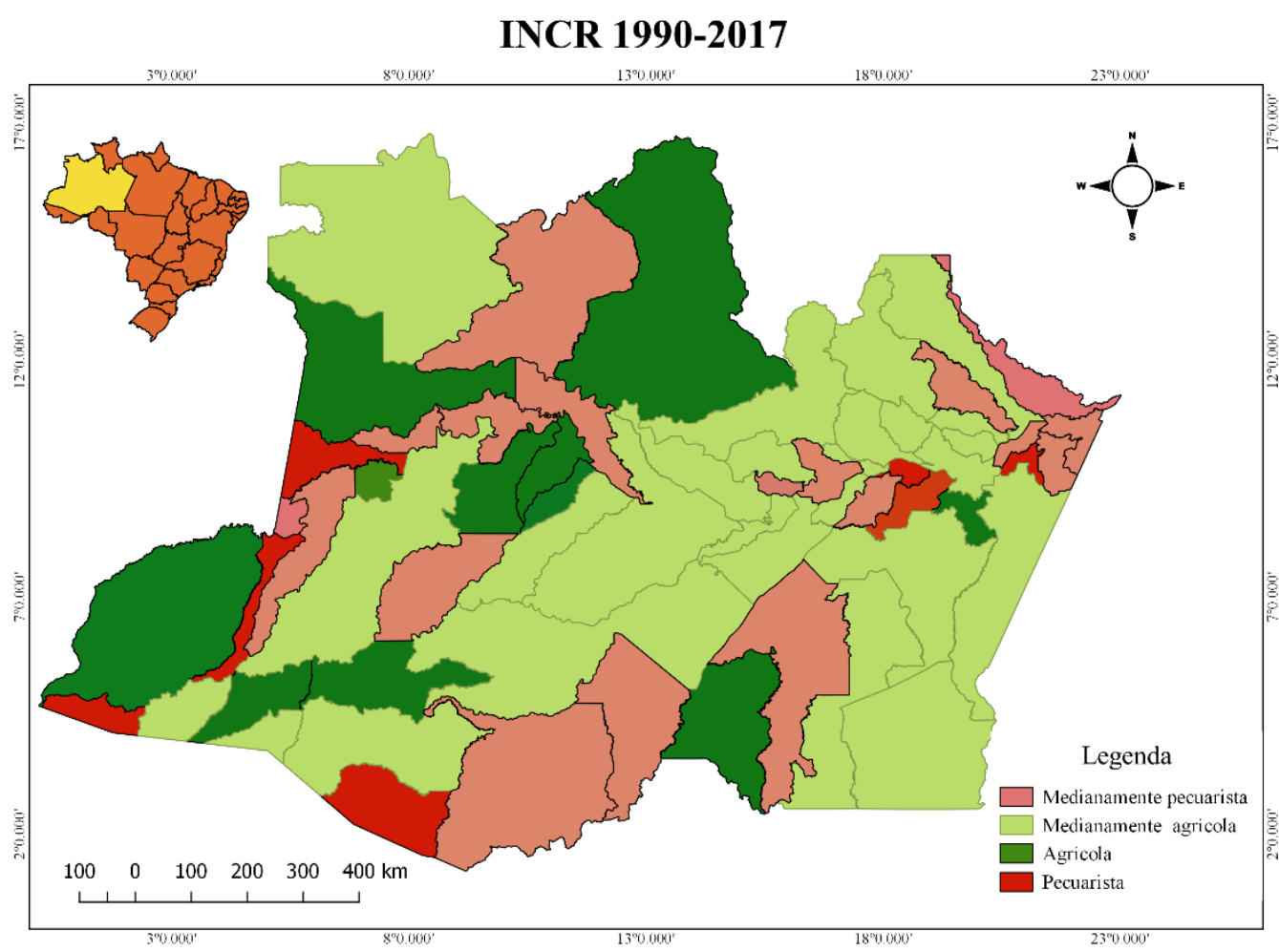

Fonte: elaborado pelos autores a partir de dados do Banco Central do Brasil (BACEN, 2018).

Tais resultados reafirmam a condição de baixo desempenho da agropecuária amazonense que necessita de maiores investimentos a partir do fortalecimento da política agrícola, particularmente de crédito, para o setor rural de forma integral.

Conforme a teoria do desenvolvimento econômico de Schumpeter (1982), o desenvolvimento a partir do crédito é dado, ainda, pelo surgimento de novas combinações de fatores, que também pode ser entendido como as tentativas de investimento em novos setores. Diante disso, a Tabela 3 faz referência aos principais produtos financiados no Amazonas entre os anos 1990, 2000, 2010 e 2017. Na análise, é perceptível que boa parte dos produtos destacados possuem relação com a pecuária, exceto na década de 1990, em que se observou muitos investimentos para a produção de borracha.

Tabela 3 - Principais produtos financiados no Amazonas em 1990, 2000, 2010 e 2017.

\begin{tabular}{lcc}
\hline & $\mathbf{1 9 9 0}$ & \\
\hline Produtos & Operações & Valor R\$ milhões \\
Borracha (seringueira) & 134 & 24,79 \\
Bovinos - Produção de Leite & 133 & 15,18 \\
Reforma de máquinas, equipamentos e veículos & 24 & 6,28 \\
Bovinos - Produção de carne & 57 & 5,18
\end{tabular}




\begin{tabular}{|c|c|c|}
\hline $\begin{array}{l}\text { Demais produtos } \\
\text { Total Geral }\end{array}$ & $\begin{array}{c}703 \\
\mathbf{1 . 0 5 1}\end{array}$ & $\begin{array}{r}49,00 \\
\mathbf{1 0 0 , 7 1} \\
\end{array}$ \\
\hline \multicolumn{3}{|c|}{2000} \\
\hline Produtos & Operações & Valor R \$ milhões \\
\hline Leite in natura & 26 & 109,47 \\
\hline Soja & 6 & 8,35 \\
\hline Laranja & 11 & 6,02 \\
\hline Outros melhoramentos N.E & 220 & 5,33 \\
\hline Demais produtos & 2.370 & 47,00 \\
\hline Total Geral & 2.633 & $\mathbf{1 7 6 , 4 8}$ \\
\hline \multicolumn{3}{|c|}{2010} \\
\hline Produtos & Operações & Valor R\$ milhões \\
\hline $\begin{array}{l}\text { Máquinas, Aparelhos e Instrumentos para explorações } \\
\text { pecuárias }\end{array}$ & 1.285 & 15,51 \\
\hline Embarcações (pequenas embarcações) & 769 & 12,61 \\
\hline Cacau & 285 & 10,88 \\
\hline Guaraná & 399 & 10,39 \\
\hline Demais produtos & 7.052 & 125,00 \\
\hline Total Geral & 9.790 & 174,39 \\
\hline \multicolumn{3}{|c|}{2017} \\
\hline Produtos & Operações & Valor R \$ milhões \\
\hline Bovinos & 645 & 36,55 \\
\hline Cana-de-açúcar & 1 & 15,00 \\
\hline Avicultura & 20 & 11,56 \\
\hline Granjas avícolas & 11 & 4,66 \\
\hline Demais produtos & 847 & 31,00 \\
\hline Total Geral & 1.524 & 99,12 \\
\hline
\end{tabular}

Fonte: Banco Central do Brasil (BACEN, 2018).

Nota: Valores corrigidos para R\$ Mil (Base: média geral do ano de 2017) pelo IGP-DI da (FGV, 2018).

No passado, a atividade extrativa de goma contribuiu bastante para a restruturação urbana do município de Manaus, onde os administradores priorizavam obras de "embelezamento" da cidade utilizando as arrecadações financeiras provenientes da comercialização de borracha. Entretanto, devido à falta de aperfeiçoamento das técnicas que vão desde o plantio até a extração do látex, a região amazônica perdeu a posição de destaque para países asiáticos, e a partir de então, a economia sofreu vários impactos negativos ocasionados pela diminuição dos preços pagos pela tonelada de borracha ainda na primeira década do século XX (NETO; NOGUEIRA, 2016).

Nos anos 2000 se destacou o leite in natura. Já em 2010, as máquinas e equipamentos para explorações pecuárias lideraram os financiamentos e em 2017, a maioria dos recursos foram destinados para a criação de bovinos.

Assim, a teoria de Schumpeter (1982) se encontra alinhada com a realidade deste estado no que diz respeito ao surgimento de novas combinações de fatores. Contudo, adaptando este pensamento para a realidade do estado, pode-se dizer que o Amazonas teve, 
na verdade, algumas tentativas de investimento em novas combinações, isto porque historicamente, com o declínio no mercado da borracha o Amazonas precisou investir em outras atividades para a geração de renda como, por exemplo, o cultivo de guaraná, cacau, cana-de-açúcar e criação animal, embora as inciativas agrícolas não tenham tido muito sucesso por conta da falta de estímulos resultantes da estratégia de desenvolvimento baseada em um modelo industrial dependente de tecnologica e importação de produtos eletrônicos na Zona Franca de Manaus (SANTOS; FRANÇA, 2018).

Nas análises desenvolvidas a partir do Índice de Gini, considerando as operações e valor das contratações de crédito agrícola, pecuário e total, os resultados demonstraram que há uma elevada concentração na alocação dos recursos, pois os valores médios do período ficaram todos na faixa de 0,74 e 0,84 tanto para operações quanto para o valor contratado.

De modo geral, os resultados das correlações (r) mostram que os impactos da política de crédito são maiores na produção animal, haja vista que os coeficientes de correlação de Pearson foram de valores moderados partindo-se do pressuposto que quanto mais próximo de 1, maior a correlação dos dados. Entende-se, portanto que de fato o crédito contribui para o desenvolvimento destas atividades, principalmente quando se trata dos efetivos de rebanho bovino e produção de ovos, pois apresentaram os maiores coeficientes e graus de confiabilidade dos resultados, sendo ambos significativos a $1 \%$, segundo o teste t de Student (Tabela 4).

Tabela 4 - Coeficientes de correlação de Pearson (r) entre as variáveis efetivo do rebanho bovino, galináceo, número de vacas ordenhadas e produção de leite e ovos em relação ao valor do crédito pecuário alocado.

\begin{tabular}{ll}
\hline Atividade & $(\mathbf{r})$ \\
\hline Efetivo Bovino & $0,4872^{* *}$ \\
Efetivo Galináceo & $0,4251^{*}$ \\
Vacas Ordenhadas & $0,3875^{*}$ \\
Leite & 0,1973 n.s \\
Ovos & $0,4818^{* *}$ \\
\hline
\end{tabular}

Fonte: dados da pesquisa (2018).

Nota: $(*)$ - Significativo a 5\% (**) - Significativo a $1 \%($ n.s) - Não Significativo

Contudo, é importante destacar que o desempenho da produção animal amazonense ainda está muito aquém de outros estados da região Norte como o Pará, Rondônia e Tocantins. 
Fato que está associado à baixa participação do estado do Amazonas no total de recursos acumulados do país. A pecuária leiteira do Amazonas retrata bem estes gargalos, pois ainda adota sistemas de criação de animais com pouca especialização, tendo em vista que o leite foi o único produto de origem animal cuja produção não apresentou correlação com o crédito, indicando que os recursos financeiros não têm sido alocados adequadamente nessa atividade, principalmente com vistas a elevar seu padrão tecnológico e de especialização.

Situação similar à produção de leite foi observada ao analisar a relação entre o crédito e o crescimento da produção agrícola. Em que, diferentemente do setor pecuário no geral, praticamente não houve correlação entre as variáveis analisadas. De modo que para todas as culturas se observou um valor de correlação muito baixo, inferindo que o crédito agrícola praticamente não resulta em efeitos positivos o suficiente para melhorar o desempenho produtivo das lavouras (Tabela 5).

Tabela 5- Coeficientes de correlação de Pearson (r) entre as principais lavouras temporárias e permanentes em relação ao valor do crédito agrícola alocado.

\begin{tabular}{lccc}
\hline \multirow{2}{*}{ Culturas } & Área Colhida & Quantidade Produzida & Produtividade \\
\cline { 2 - 4 } & $0,2939 \mathrm{n} . \mathrm{s}$ & $0,1716 \mathrm{n} . \mathrm{s}$ & $0,0681 \mathrm{n} . \mathrm{s}$ \\
\hline Abacaxi & $0,0991 \mathrm{n} . \mathrm{s}$ & $0,1118 \mathrm{n} . \mathrm{s}$ & $0,1833 \mathrm{n} . \mathrm{s}$ \\
Arroz & $0,2891 \mathrm{n} . \mathrm{s}$ & $0,3548 \mathrm{n} . \mathrm{s}$ & $0,2582 \mathrm{n} . \mathrm{s}$ \\
Cana-de-açúcar & $0,3311 \mathrm{n} . \mathrm{s}$ & $0,3471 \mathrm{n} . \mathrm{s}$ & $-0,1575 \mathrm{n} . \mathrm{s}$ \\
Mandioca & $0,158 \mathrm{n} . \mathrm{s}$ & $0,0712 \mathrm{n} . \mathrm{s}$ & $-0,3925^{*}$ \\
Malva & $0,3564 \mathrm{n} . \mathrm{s}$ & $0,3432 \mathrm{n} . \mathrm{s}$ & $0,2394 \mathrm{n} . \mathrm{s}$ \\
Melancia & $0,3698 \mathrm{n} . \mathrm{s}$ & $0,4607 *$ & $0,1666 \mathrm{n} . \mathrm{s}$ \\
Milho & $0,3473 \mathrm{n} . \mathrm{s}$ & $-0,2846 \mathrm{n} . \mathrm{s}$ & $-0,3464 \mathrm{n} . \mathrm{s}$ \\
Laranja & $0,0302 \mathrm{n} . \mathrm{s}$ & $0,0267 \mathrm{n} . \mathrm{s}$ & $0,1634 \mathrm{n} . \mathrm{s}$ \\
Banana & $0,3806 *$ & $0,4343 *$ & $0,1881 \mathrm{n} . \mathrm{s}$ \\
Cacau & $0,1222 \mathrm{n} . \mathrm{s}$ & $0,1086 \mathrm{n} . \mathrm{s}$ & $0,0865 \mathrm{n} . \mathrm{s}$ \\
Guaraná & $0,1321 \mathrm{n} . \mathrm{s}$ & $0,0245 \mathrm{n} . \mathrm{s}$ & $-0,1296 \mathrm{n} . \mathrm{s}$ \\
Mamão & $0,2134 \mathrm{n} . \mathrm{s}$ & $-0,0643 \mathrm{n} . \mathrm{s}$ & $-0,2002 \mathrm{n} . \mathrm{s}$ \\
Maracujá & & &
\end{tabular}

Fonte: Dados da pesquisa (2018).

Nota: (*) Significativo a 5\%; (**) Significativo a 1\%; (n.s) Não Significativo.

Em alguns casos, inclusive, o valor do coeficiente foi negativo, indicando que a aplicação dos recursos não tem influências sobre o comportamento destas variáveis. Com isso, no cerne das discussões a respeito da política de crédito no Amazonas estão as grandes limitações e defasagens no sistema, que acaba criando uma concentração dos recursos por meio do maior número de operações de alto valor destinadas ao financiamento da pecuária. 


\section{CONCLUSÃO}

Constata-se uma grande concentração na alocação dos recursos de crédito rural no estado do Amazonas, haja vista que os valores médios do Índice de Gini variaram entre 0,74 e 0,84 nos créditos agrícola e pecuário. O Índice Normalizado de Crédito Rural (INCR) permitiu identificar a presença de um maior número de municípios que exercem atividades agrícolas, embora este seja um setor com baixo desempenho no estado. Com isso, o que se percebe é que há um grande número de municípios atendidos com operações de crédito de baixo valor, enquanto poucos municípios captam a maior parcela dos recursos, cuja finalidade é a criação de animais. Além disso, os resultados provenientes da correlação de Pearson permitiram identificar que a aplicação destes recursos não apresenta forte correlação com o crescimento da produção agrícola, cuja performance é muito limitada. Diferentemente do observado na pecuária, onde o crédito se correlaciona positivamente com o crescimento de todas as atividades, exceto a produção de leite.

Espera-se, portanto, que a realização de estudos dessa natureza contribua para orientar as decisões dos agentes de política agrícola, produtores e empresários quanto à alocação dos recursos de crédito rural no estado do Amazonas. Isso é importante para aumentar a eficiência do setor e diminuir a pressão sobre os recursos naturais, por meio da intensificação da produção via aumento da produtividade da terra.

\section{REFERÊNCIAS}

ALMUDI, T.; PINHEIRO, J. O. C. Dados estatísticos da produção agropecuária e florestal do estado do Amazonas: ano 2013. Brasília, DF: Embrapa Amazônia Ocidental, 2015. 105 p. Disponível em:<https://ainfo.cnptia.embrapa.br/digital/bitstream/item/127984/1 /Livro-GCEA.pdf>. Acesso em 19 set. 2018.

ALVES, E. R. A.; CONTINI, E.; GASQUES, J. Evolução da produção e produtividade da agricultura Brasileira. In: ALBUQUERQUE, A. C. S.; SILVA, A. G. da (Ed.). Agricultura tropical: quatro décadas de inovações tecnológicas, institucionais e políticas. Brasília, DF: Embrapa Informação Tecnológica, 2008. v.1, p. 67. Disponível em:<https://ainfo.cnptia.embrapa.br/digital/bitstream/item/153552/1/Evolucao-daproducao.pdf $>$. Acesso em: 18 set. 2018.

ARAÚJO, B. C.; LEYI LI, D. Crédito Rural. In: DE NEGRI, J. A.; ARAÚJO, B. C.; BACELETTE, R. (Org.). Financiamento do desenvolvimento do Brasil. Brasília: IPEA, 2018. 316 p. Disponível em:<https://www.ipea.gov.br/portal/index.php?option=com_content\&view=article\&id=3437 $>$. Acesso em: 18 set. 2018. 
ARAUJO, J. A.; VIEIRA FILHO, J. E. R. Análise dos impactos do PRONAF na agricultura do Brasil e no período de 2007 a 2016. Brasília: IPEA, 2018, 52 p. (Texto para discussão no 2412). Disponível em:<http://repositorio.ipea.gov.br/bitstream/11058/8696/1/td_2412_.pdf >. Acesso em: 17 set. 2018.

ARAÚJO, K. S.; PEREIRA, H. S. Políticas públicas e as fibras naturais: a experiência recente da cadeia produtiva da malva e juta Amazônica. Revista de Ciências Agrárias, Belém, v. 60, n. 1, p. 60-69, Jan-Mar. 2017. Disponível em:<http://ajaes.ufra.edu.br/index.php/ajaes/article/view/2656>. Acesso em: 21 set. 2018.

BANCO CENTRAL DO BRASIL. Anuário Estatístico do Crédito Rural. Disponível em: <https://www.bcb.gov.br/estabilidadefinanceira/anuario_estat_credrural >. Acesso em: 20 set. 2018.

BANCO CENTRAL DO BRASIL. Matriz de Dados do Crédito Rural. Disponível em:<https://www.bcb.gov.br/estabilidadefinanceira/micrrural>. Acesso em: 20 set. 2018.

BELIK, W. O Financiamento da agropecuária brasileira no período recente. IPEA: Brasília, 2015, 64 p. (Texto para discussão no 2028). Disponível em: <http://www.ipea.gov.br/portal/images/stories/PDFs/TDs/td_2028.pdf>. Acesso em: 16 set. 2018.

BENCHIMOL, S. Amazônia: um pouco-antes e além-depois. Manaus: Ed. Umberto Calderaro, 1977.

CARRERO, G. C.; ALBUJA, G.; FRIZO, P.; HOFFMAN, E. K.; ALVES, C.; BEZERRA, C. S. A cadeia produtiva da carne bovina no Amazonas. Manaus: IDESAM, 2015. Disponível em:<https://d3nehc6yl9qzo4.cloudfront.net/downloads/cadeia_produtiva_corte_amazonas.pd >. Acesso em: 19 set. 2018.

CASTRO, P. R. V. DO ESTADO AO MERCADO: a trajetória do crédito rural Brasileiro e as diversas fontes de financiamento, período colonial ao século XXI. Informações Econômicas, SP, v. 47, n. 3, jul./ set. 2017. Disponível em:<http://www.iea.sp.gov.br/ftpiea/ie/2017/tec40717.pdf>. Acesso em: 19 set. 2018.

CRUZ, F. G. G.; RUFINO, J. P F.; MELHO, R. D.; FEIJÓ, J. C.; DAMASCENO, J. L.; COSTA, A. P. G. C. Perfil socioeconômico da avicultura no setor primário do estado do Amazonas, Brasil. Revista em Agronegócio e Meio Ambiente, v. 9, n. 2, p. 371-391, 2016. Disponível em:<https://periodicos.unicesumar.edu.br/index.php/rama/article/view/4321>. Acesso em: 15 de out. 2020.

CUENCA, M. A. G.; DOMPIERI, M. H. G.; SÁ, H. A. Análise dos efeitos dos fatores de variação do valor bruto da produção de milho por meio do modelo Shift-Share, no estado de Sergipe. Aracaju, SE: Embrapa Tabuleiros Costeiros, 2015, 29 p. (Boletim de pesquisa $\left.\mathrm{n}^{\circ} 101\right)$. Disponível em: <https://www.infoteca.cnptia.embrapa.br/infoteca/bitstream/doc/1042175/1/BP101.pdf >. Acesso em: 18 set. 2018. 
EMPERAIRE, L.; ELOY, L. A cidade, um foco de diversidade agrícola no Rio Negro (Amazonas, Brasil). Boletim do Museu Paraense Emílio Goeldi Ciências Humanas, v. 3, n. 2, p. 195-211, 2008. Disponível

em:<https://www.scielo.br/scielo.php?script=sci_arttext\&pid=S1981-81222008000200005>. Acesso em: 15 out. 2020.

FERNANDES, F. Instituto Internacional de Educação do Brasil - IEB: Potencialidades e limites da cadeia de valor do cacau (Theobromacacao) no município de Manicoré, Sul do Amazonas. 2016. Disponível em:<http://www.fundovale.org/wpcontent/uploads/2017/10/3_cacau_manicore.pdf>. Acessoem: 21 set. 2018.

FREE SOFTWARE FOUNDATION - FSF. Gnu regression, econometrics and time-series library. Boston: FSF, 2017. Disponível em:<http://gretl.sourceforge.net/pt.html>. Acesso em: 27 ago. 2018.

FUNDAÇÃO GETÚLIO VARGAS. FGVDADOS: Informação Econômica On-line. Disponível em:<http://fgvdados.fgv.br> Acesso em: 27 ago. 2018.

HOFFMANN, R. Estatística para economistas. 2. ed. São Paulo: Livraria Pioneira Editora. 1991. 426p.

HOMMA, A. K. O. (Ed.). Extrativismo vegetal na Amazônia: história, ecologia, economia e domesticação. Brasília, DF: Embrapa Amazônia Oriental, 2014. 468 p. Disponível em:<https://www.embrapa.br/amazonia-oriental/busca-de-publicacoes//publicacao/1016352/extrativismo-vegetal-na-amazonia-historia-ecologia-economia-edomesticacao>. Acesso em: 18 set. 2018.

HOMMA, A. K. O. Fontes de crescimento da agricultura paraense, 1970/80. Belém, PA: Embrapa CPATU, 1981. (Boletim de pesquisa n ${ }^{\circ} 27$ ). Disponível em:<https://www.infoteca.cnptia.embrapa.br/infoteca/handle/doc/380315>. Acesso em: 27 ago. 2018.

INSTITUTO BRASILEIRO DE GEOGRAFIA E ESTATÍSTICA. Sistemade Recuperação Automática de dados - SIDRA. Produção Agrícola Municipal. Disponível em: <https://sidra.ibge.gov.br/pesquisa/pam/tabelas>. Acesso em 16 nov. de 2018a.

INSTITUTO BRASILEIRO DE GEOGRAFIA E ESTATÍSTICA. Sistema de Recuperação Automática de dados - SIDRA. Produção Pecuária Municipal. Disponível em: <https://sidra.ibge.gov.br/pesquisa/ppm/quadros/brasil/2017>. Acesso em 16 nov. de 2018b.

INSTITUTO BRASILEIRO DE GEOGRAFIA E ESTATÍSTICA. Sistemade Recuperação Automática de dados - SIDRA. Estimativas de População. Disponível em: $<$ https://sidra.ibge.gov.br/pesquisa/estimapop/tabelas>. Acesso em 20 de out. 2020.

LIMA, R. A. S. Informação, capital social e mercado de crédito rural. São Paulo, 2003. 107f. Tese (Doutorado em Economia) Programa de Pós-Graduação em Economia Aplicada, Escola Superior de Agricultura Luiz de Queiroz, Piracicaba, 2003. Disponível em: <https://www.teses.usp.br/teses/disponiveis/11/11132/tde-14072003-094610/pt-br.php>. Acesso em 18 set. 2018. 
LOPES, D.; LOWERY, S.; PEROBA, T. L. C. Crédito rural no Brasil: desafios e oportunidades para a promoção da agropecuária sustentável. Revista do BNDES. v. 45, p. 155-196, jun. 2016. Disponível em:<https://web.bndes.gov.br/bib/jspui/handle/1408/9518>. Acesso em: 18 set. 2018.

MENEGHETTI, G. A.; SOUZA, S. R. A agricultura familiar do Amazonas: conceitos, caracterização e desenvolvimento. Revista Terceira Margem Amazônica, v. 1, n. 5, p. 3558, 2015. Disponível em:

<http://www.revistaterceiramargem.com/index.php/terceiramargem/article/view/54>. Acesso em: 19 de out. 2020.

NASCIMENTO, M. N. C. F.; SANTOS, M. A. S.; ALMEIDA, R. H. C. Evolução e distribuição espacial das aplicações de crédito rural no estado do Amapá na primeira década do século 21. PRACS: Revista Eletrônica de Humanidades do Curso de Ciências Sociais da UNIFAP, v. 4, p. 79-94, 2011. Disponível em:<https://periodicos.unifap.br/index.php/pracs/article/view/363>. Acesso em 18 set. 2018.

NEGRI NETO, A.; COELHO, P. J.; MOREIRA, I. R. O. Análise gráfica e taxa de crescimento. Informações Econômicas, v. 23, n. 10, p. 99-108, 1993. Disponível em: $\langle$ http://www.iea.sp.gov.br/out/LerTexto.php?codTexto=1327>. Acesso em: 19 de out. 2020.

NEPSTAD, D. C.; STICKLER, C. M.; ALMEIDA, O. Globalization of the Amazon soy and beef industries: opportunities for conservation. Conservation Biology, v. 20, n. 6, p. 15951603, mar. 2006. Disponível em:<https://www.ncbi.nlm.nih.gov/pubmed/17181794>. Acesso: 25 de set. 2018.

NETO, T. O.; NOGUEIRA, R. J. B. A cidade de Manaus e a crise da borracha: uma breve análise histórica. Estação Científica (UNIFAP), Macapá, v. 6, n. 3, p. 09-27, set-dez., 2016. Disponível em: $<$ https://periodicos.unifap.br/index.php/estacao/article/view/2332>. Acesso em: 24 set. 2018.

OLIVEIRA, E. C. et al. O setor de fruticultura do estado do Amazonas: análise e desafios para o desenvolvimento regional. In:Conferência Internacional de Pesquisa sobre Economia Social e Solidária, 6., 2017, Manaus. Anais... Manaus: CIRIEC, 2017.p. 1-26. Disponível em: <https://even3.blob.core.windows.net/processos/e77397e89efc45ee8c62.pdf >. Acesso em: 25 de set. 2018.

OLIVEIRA, R. P. M.; OLIVEIRA, F. F.; PASSOS, A.; LAMARÃO, C. V. Ovinos de corte no estado do Amazonas: ênfase no manejo produtivo. Revista Terceira Margem Amazônia, v. 2, n. 9, p. 140-159, 2017. Disponível

em:<http://www.revistaterceiramargem.com/index.php/terceiramargem/article/view/175>. Acesso em 20 de out. 2020.

PROGRAMA DAS NAÇÕES UNIDAS PARA O DESENVOLVIMENTO. Ranking IDHM Unidades da Federação 2010. Disponível em: https://www.br.undp.org/content/brazil/pt/home.html. Acesso em: 20 out. 2020.

RAMOS, S. Y.; MARTHA JUNIOR, G. B. Evolução da política de crédito rural Brasileira. Planaltina, DF: Embrapa Cerrados, 2010. (Documentos no 292). Disponível em: 
<https://ainfo.cnptia.embrapa.br/digital/bitstream/item/77790/1/doc-292.pdf>. Acesso em 15 de set. 2018.

REBELLO, F. K.; HOMMA, A. K. H. História da colonização do Nordeste Paraense: uma reflexão para o futuro da Amazônia. Belém: EDUFRA, 2017. 153 p.

REBELLO, F. K.; SANTOS, M. A. S.; SOUZA, D. M. F. Modernização da agricultura regional: contribuições do Banco da Amazônia no período de 1989 a 2007. Boletim Contexto Amazônico, Belém, v. 1, n. 10, p. 1-4, set. 2008. Disponível

em:<https://www.bancoamazonia.com.br/index.php/sobre-o-banco/sustentabilidade>. Acesso em: 19 set. 2018.

RESENDE, L.; ORLANDO FILHO, J. Sistema de produção do guaraná na usina Jayoro Amazonas. Revista Canavieiros, p. 100, set. 2017. Disponível

em:<https://www.revistacanavieiros.com.br>. Acesso em 20 out. 2020.

RODRIGUES, F. F. A. (Org.). Amazonas 2000-2013. São Paulo: Editora Fundação Perseu Abramo, 2016. 80 p. Disponível em:<https://fpabramo.org.br/publicacoes/wpcontent/uploads/sites/5/2017/05/Amazonas-web.pdf >. Acesso em: 14 de out. 2020.

SANTOS, G. M. dos; FRANÇA, L. R. de (Org.). GEEA: Grupo de Estudos Estratégicos Amazônicos. Manaus: Editora INPA, 2018. 64 p. (Caderno de debates). Disponível em: <http://portal.inpa.gov.br/index.php/component/content/article?id=221 >. Acesso em $20 \mathrm{de}$ out. 2020.

SANTOS, G. M. dos; PEREIRA, A. M. R. F. (Org.). GEEA: Grupo de Estudos Estratégicos Amazônicos. Manaus: Editora INPA, 2020. 58p. (Caderno de debates). Disponível em:<http://portal.inpa.gov.br/index.php/component/content/article?id=221 $>$. Acesso em 20 de out. 2020.

SANTOS, M. A. S.; REBELlO, F. K.; SANTANA, A. C. A política de crédito rural no estado do Pará: distribuição espacial e concentração das aplicações no período 2000-2010. Revista em Agronegócio e Meio Ambiente, v. 5, p. 493-508, 2012. Disponível em:<https://periodicos.unicesumar.edu.br/index.php/rama/article/view/2115>. Acesso em: 19 set. 2018

SCHOR, T.; MARINHO, T. P. Ciclos econômicos e periodização da rede urbana no Amazonas-Brasil: as cidades de Parintins e Itacoatiara de 1655 a 2010. Revista do Instituto de Estudos Brasileiros, São Paulo, n. 56, p. 229-258, jun 2013. Disponível em:<http://www.revistas.usp.br/rieb/article/view/69000>. Acesso em: 14 de out. 2020.

SCHUMPETER, J. A. Teoria do Desenvolvimento Econômico: uma investigação sobre lucros, capital, crédito, juros e o ciclo econômico. São Paulo: Ed. Abril Cultural, 1982.

SEDECTI, Secretaria do Estado de Desenvolvimento Econômico, Ciência, Tecnologia e Inovação. Amazonas em Mapas. Disponível em:<http://www.sedecti.am.gov.br/wpcontent/uploads/2019/07/1a_Amazonas_em_Mapas_2015_em_novembro_de_2016.pdf>. Acesso em 17 de janeiro de 2019. 
SILVA NETO, J. C. A. da; ALEIXO, N. C. R.; DIAS, L. S. (Org.). Dinâmicas socioambientais na Amazônia Brasileira. 1. ed. São Paulo: ANAP, 2017. Disponível em:<http://professor.ufrgs.br/dagnino/files/dagnino_2017_cap_livro_tao_longe_tao_perto_at m_sfx.pdf $>$. Acesso em: 17 de set. 2020.

SILVA, A. C. B.; CARRERO, G. C. Pecuária de leite em sistema silvipastoril com pastejo rotacional no Sul do Amazonas. Manaus: IDESAM, 2018, 586 p. Disponível em: $\langle$ https://idesam.org/publicacao/viabilidade-pecuaria-leite-apui.pdf $>$. Acesso em: 16 de nov. 2018.

SILVA, A. L. Entre tradições e modernidade: conhecimento ecológico local, conflitos de pesca e manejo pesqueiro no Rio Negro, Brasil. Boletim do Museu Paraense Emílio Goeldi Ciências Humanas, v. 6, n. 1, p. 141-163, 2011. Disponível em:<https://repositorio.unesp.br/handle/11449/27067>. Acesso em: 15 de out. 2020.

SOUSA, S. B.; FERREIRA JUNIOR, L. G.; MIZIARA, F.; MORAIS, H. A. Crédito rural no Brasil: evolução e distribuição espacial (1969-2016). Confins, n. 45, 2020. Disponível em:<https://journals.openedition.org/confins/29836>. Acesso em: 20 de out. 2020.

SOUZA, C. C. M.; SANTOS, M. A. S.; REBELLO, F. K. Espacialização e concentração das aplicações de crédito rural no Brasil entre 2007 e 2017. Agrarian Academy, Centro Científico Conhecer, Goiânia, v. 5, n. 10, p. 82-92, 2018. Disponível em:<http://www.conhecer.org.br/Agrarian\%20Academy/2018B/espacializacao.pdf >. Acesso em: 21 set. 2018.

SOUZA, P. M.; BARBÉ, L. C. Desigualdades regionais na distribuição dos financiamentos do PRONAF: uma análise do período de 1998 a 2012. Revista Econômica do Nordeste. Fortaleza, v. 45, p. 31-43, 2014. Disponível em:<https://ren.emnuvens.com.br/ren/article/view/497>. Acesso em: 16 de set., 2018.

SOUZA, P. M.; NEY, M. G.; PONCIANO, N. J. Análise da distribuição dos financiamentos rurais entre os estabelecimentos agropecuários Brasileiros. Revista de Economia e Sociologia Rural, Piracicaba-SP, v. 53, n. 2, p. 251-270 abr./jun. 2015. Disponível em:<https://www.scielo.br/pdf/resr/v53n2/1806-9479-resr-53-02-00251.pdf>. Acesso em: 16 de set. 2018.

VILAS BOAS, H. C. Multiplicação induzida de colmeias de abelhas Melipona seminigra Friese, 1903 (Hymenoptera, Apidae) submetidas a diferentes tipos de alimentação complementar, em Manaus - AM. Amazonas, 2012. 79 f. Dissertação (Mestrado em Agricultura no Trópico Úmido) Programa de Pós-Graduação em Agricultura no Trópico Úmido. Instituto Nacional de Pesquisas na Amazônia, Manaus.2012. Disponível em:<https://bdtd.inpa.gov.br/handle/tede/1685\#preview-link0>. Acesso em: 21 de set. 2018.

Recebido: 17/05/2020

Aceito: 19/09/2020

Publicado: outubro de 2020. 